\title{
Exploring New NSM Reinforcements for the Flexural Strengthening of RC Beams: Experimental and Numerical Research
}

\author{
Mohammadali Rezazadeh ${ }^{1}$, Szymon Cholostiakow ${ }^{2}$, Renata Kotynia ${ }^{3}$, Joaquim Barros ${ }^{4}$
}

\begin{abstract}
:
Carbon-fiber-reinforced-polymer (CFRP) composite materials applied according to near-surface-mounted (NSM) technique constitute an effective technique for the flexural and shear strengthening of reinforced-concrete (RC) structures. However, the NSM CFRP reinforcement ratio is limited by the thickness of concrete cover of the longitudinal tensile steel bars, and the minimum distance between consecutive CFRPs, below which premature fracture of surrounding concrete occurs due to group effect. Hence, the current study aims to experimentally and numerically evaluate the strengthening potentialities of a novel NSM system (with high CFRP ratio capability) for the flexural strengthening of RC beams. This new system combines externally-bonded-reinforcement (EBR) and NSM techniques in the same application using T-shaped CFRP profiles. The obtained experimental results of the RC beams strengthened with CFRP profiles are presented and discussed with the aim of evaluating the influence of CFRP profile reinforcement ratio on the strengthening efficiency of this technique. A developed 3D finite-element (FE) approach is used to simulate the experimental tests. After demonstrating its good predictive performance, a series of parametric studies is performed to assess the influence of the main material properties, and ratio of bond area to cross sectional area of the CFRP profiles on the efficiency of the proposed system.
\end{abstract}

Keywords: Carbon fiber reinforced polymer; T-shaped CFRP profile; Flexural strengthening; RC beams; FEM; Material nonlinear analysis; Parametric studies.

\footnotetext{
${ }^{1}$ Dr., ISISE, Dep. of Civil Eng., University of Minho, Azurém, 4810-058 Guimarães, Portugal, rzh.moh@gmail.com.

${ }^{2}$ PhD Student, Dep. of Civil Eng., Lodz University of Technology, Al. Politechniki 6, 90-924, Lodz, Poland / The University of Sheffield, Sheffield, UK, s.cholostiakow@ sheffield.ac.uk.

${ }^{3}$ Associated Prof., Dep. of Civil Eng, Lodz University of Technology, Al. Politechniki 6, 90-924, Lodz, Poland, renata.kotynia@p.lodz.pl.

4 Full Prof., ISISE, Dep. of Civil Eng., University of Minho, Azurém, 4810-058 Guimarães, Portugal, barros@civil.uminho.pt.
} 


\section{INTRODUCTION}

Carbon fiber reinforced polymer (CFRP) materials exhibit high tensile strength and relatively high elasticity modulus in comparison to other FRP materials that makes them good candidates to constitute effective structural strengthening solutions for existing reinforced concrete (RC) structures. The mechanical attributes of the composites are complemented with additional advantages like lightweight, high durability, and a good magnetic and dynamic resistance [1-4].

High efficiency on the flexural strengthening with passive and active externally bonded (EB) CFRP materials has been confirmed in many research projects and practical applications [5]. However, the maximum tensile strength that can be mobilized in the composites applied according to the EB technique is limited by the bond performance between FRP systems and concrete substrate. Moreover, FRPs applied according to the EB technique are susceptible to the detrimental effects of UV, fire exposure, and vandalism acts [5].

In an attempt of attenuating these problems, near surface mounted (NSM) technique has been proposed, consisting on the installation of thin laminates or bars into slits opened into the concrete cover of the elements to be strengthened $[6,7]$. This technique enables relative fast application without any special preparation of the concrete substrate, which is a further advantage for the strengthening of existing RC structures. The most popular FRP strips used in NSM applications have cross section with a width in the range of 1.2 to $4.5 \mathrm{~mm}$ and a height from 9 to $25 \mathrm{~mm}$, while the circular bars have a diameter from 9 to $12.7 \mathrm{~mm}[6]$.

The NSM system has significantly provided better composite-to-concrete bond behavior due to its larger ratio of bond area to cross sectional area of the FRP reinforcement, and higher confinement provided by the surrounding concrete to this reinforcement [8]. This fact has made this technique the most effective from the existing non-prestressed strengthening solutions. High efficiency of NSM technique in the flexural strengthening of RC members has been proved in many tests $[7,9-16]$. The NSM technique significantly increased the load carrying capacity, and the FRP tensile strain utilization up to 80-90\% in comparison to EB FRP applications [6, 17].

However, the flexural strengthening efficiency of NSM technique is limited to the cross section's height of the FRPs, which should be lower than the thickness of the concrete cover of the longitudinal tensile steel reinforcement. In this regard, experimental results showed that cutting the bottom arm of steel stirrups for the installation of CFRP laminates 
with relatively large cross section's height had a marginal impact in terms of the flexural strengthening effectiveness of the NSM technique for monotonic loading conditions $[7,17,18]$.

Besides the extensive experimental application of FRP systems for the flexural and shear strengthening of RC structures, numerical analyses are also necessary to evaluate the influence of the several parameters on the strengthening efficiency of FRP techniques. Hence, numerical analysis of FRP strengthened structures have been correspondingly carried out for simulating the experimental results. Many researchers simulated the behavior of NSM CFRP strengthened structures using 2D or 3D numerical models considering perfect bond conditions (no-slip occurrence) $[19,20]$. However, these types of numerical strategies are not capable of predicting the FRP debonding failure, which can conduct to incorrect estimations of the maximum flexural capacity of the FRP strengthened structures since it can occur before the conventional flexural failure modes (concrete crushing and rupture of the CFRP reinforcement) and other premature failure modes (such as concrete cover delamination and tensile concrete cover splitting failure) [21, 22]. Finite element (FE) modeling of NSM CFRP strengthened structures considering debonding effects is, however, very limited [23, 24]. Therefore, developing a FE model of RC structures strengthened using NSM FRP reinforcement considering the nonlinear behavior of constituent materials and FRP-epoxy-concrete interfaces seems still necessary for contributing for the understanding of the failure mechanisms involved.

The current study aims to experimentally and numerically evaluate the strengthening potentialities of a novel NSM system for the flexural strengthening of RC beams. This new system combines EBR and NSM techniques in the same application using T-shaped CFRP profiles (named T-NSMR). According to this system, the web of the T-shaped profile is bonded into the longitudinal slot cut in the concrete cover and the horizontal flange of the profile is externally bonded on the bottom concrete surface. In this regard, an experimental program was organized in the Lodz University of technology to evaluate the strengthening efficiency of this new technique [25]. In the present paper, first the obtained experimental results in terms of the flexural response and prevailing failure modes of the RC beams strengthened with CFRP profiles are presented and discussed with the aim of evaluating the influence of the CFRP profile reinforcement ratio on the strengthening efficiency of the proposed technique. A developed 3D finite element (FE) approach is then used to simulate the experimental tests. The FE model considers the nonlinear behavior of the constituent materials and the behavior of concrete-adhesive-CFRP interfaces. After demonstrating the good predictive performance of the adopted numerical strategy, a series of parametric studies is performed to numerically assess the 
influence on the strengthening efficiency of the proposed new system of the properties of concrete and CFRP profiles, and ratio of bond area and cross sectional area of the CFRP profiles.

\section{EXPERIMENTAL PROGRAM}

A series of five full-scale RC beams, which were part of a wider research program, were tested at the Laboratory of Concrete Structures in Lodz University of Technology. The tested RC beams, with a rectangular cross section of 270 $\mathrm{mm}$ wide and $550 \mathrm{~mm}$ height and a clear span of $4000 \mathrm{~mm}$, had the same steel reinforcement and concrete strength (Fig. 1). The ordinary steel reinforcement consisted of two bars of $14 \mathrm{~mm}$ diameter in tension and two bars of $12 \mathrm{~mm}$ diameter in compression (Fig. 1). To prevent shear failure of the beams, two bent bars of $14 \mathrm{~mm}$ diameter and vertical stirrups of $8 \mathrm{~mm}$ diameter at $100 \mathrm{~mm}$ spacing were applied in the shear span. The stirrups spacing was $200 \mathrm{~mm}$ in the pure bending region of $1200 \mathrm{~mm}$ length. Simply supported beams were tested in six point bending loading configuration. The tests were carried out in load control, by using four hydraulic actuators equipped with servo-valves. To simulate a real bending moment envelope corresponding to a uniform loading, common for the real RC structures in bending, four point loads were applied directly to the top site of each beam with two different loading rates of 0.7 kN/min (two outermost loads) and $1.0 \mathrm{kN} / \mathrm{min}$ (two innermost loads) (see Fig. 1). The current experimental program was organized with special focus on the CFRP reinforcement ratio $\left(\varsigma_{f}\right)$ that varied from $0.11 \%$ to $0.32 \%$.

\subsection{Material Properties}

The beams were made of the same class of concrete, assumed as C50/60. The mean values of concrete strength and elasticity modulus ( $E_{c m}=34.5 \mathrm{GPa}$ ) for each beam were separately determined on cubic specimens of $150 \mathrm{~mm}$ ( $\left.f_{\text {ccm, }, \text { cube }}=60.1 \mathrm{MPa}\right)$ and cylinder specimens of $150 \mathrm{~mm}$ diameter and $300 \mathrm{~mm}$ height $\left(f_{\text {ccm,cyl }}=48.4 \mathrm{MPa}\right)$ on the testing day, according to EN 206-1.

A mean yielding strength, ultimate tensile strength, and elasticity modulus of the steel reinforcement were determined in the tensile tests, as $f_{\text {sym }}=523 \mathrm{MPa}, f_{\text {sum }}=635 \mathrm{MPa}$ and $E_{\text {sm }}=209 \mathrm{GPa}$, respectively, according to EN 10002. 
Based on the tensile tests of CFRP strips conducted according to the ASTM D3039, the following properties were determined: a mean value of the tensile strength, $f_{\text {fum }}=1673 \mathrm{MPa}$, corresponding ultimate strain, $\varepsilon_{\text {fum }}=1.08 \%$, and elasticity modulus, $E_{f m}=149 \mathrm{GPa}$. Two component epoxy adhesive was used for bonding the CFRP profiles to the concrete.

\subsection{Strengthening Configuration}

One reference beam was unstrengthened, while the remaining four beams were strengthened using one or two CFRP pultruded profiles with different web height (Fig. 2). A beam's designation indicates the FRP reinforcement (e.g. 2T15 identifies the beam strengthened with two T-shaped CFRP profiles of $15 \mathrm{~mm}$ web height and 1T-30 identifies the beam strengthened with one CFRP profile of $30 \mathrm{~mm}$ web height). The embedment length of all CFRP profiles equals to $3760 \mathrm{~mm}$. Rectangular grooves with dimensions of $8 \times 18 \mathrm{~mm}$ or $8 \times 33 \mathrm{~mm}$ were used for the application of the T15 and T-30 T-shaped profiles, respectively (Fig. 2c). The strengthening procedure consisted of making the grooves cutting along the bottom surface of the beam, applying epoxy on CFRP profile's flange and into the grooves, introducing the profile into the groove and pressing it until the bond agent completely filled the slot. The epoxy adhesive curing took at least seven days before testing the corresponding beam. The application of T-30 profiles had required cutting the bottom arm of the steel stirrups through the whole length of the profile (see Fig. 2c).

\subsection{Instrumentation}

Deflections were measured using nine vertical LVDTs (V1 - V9) placed along the span of the beam, as shown in Fig. 3a. Concrete strains at the level of longitudinal steel reinforcement were measured by five LVDTs placed in compression (Rc1 - Rc5) and eleven gauges introduced in tension (Rt1 - Rt11). Strains in the CFRP profiles were registered by seven strain gauges (T1p - T7p) located along the flange of each profile (see Fig. 3b). Two additional strain gauges (Tsr1 - Tsr2) were applied on the web of the CFRP profile, and two others (Ts1 - Ts2) were located on the tensile steel bars (Fig. 3c). 


\section{TEST RESULTS}

The main results from the experimental program are listed in Table 1 in terms of total cracking load $\left(F_{c r}(1)\right)$, total yielding load $\left(F_{y}(3)\right)$ and total ultimate load $\left(F_{u}(5)\right)$, as well as their corresponding deflections $(2,4,6)$. Moreover, the strengthening efficiency ratio $\left(\eta_{f}(7)\right)$ in this table is calculated from:

$$
\eta_{f}=\frac{F_{u}-F_{0}}{F_{0}} \cdot 100 \%
$$

where $F_{u}$ and $F_{0}$ are the ultimate load of the strengthened and unstrengthed beams, respectively.

Table 1 also reports the maximum tensile strains in the flange $\left(\varepsilon_{f, \text { flange }}(8)\right)$ and in the web $\left(\varepsilon_{f, w e b}(9)\right)$ of the CFRP profiles, and the ratio $\left(\eta_{\varepsilon}(10)\right)$ between the maximum strain in the CFRP profile $\left(\varepsilon_{f, \max }\right)$ and its ultimate average tensile strain (obtained from the material tests $\left(\varepsilon_{f u}\right)$ ), which is calculated according to:

$$
\eta_{\varepsilon}=\frac{\varepsilon_{f, \max }}{\varepsilon_{f u}} \cdot 100 \%
$$

Failure modes of the tested beams are also summarized (11) in Table 1 and in the following the relevant aspects are highlighted. The reference beam (Ref) was designed to fail in bending due to the yielding of the tensile steel reinforcement (SY) followed by the concrete crushing (CC), and characterized by the symbols SY+CC (see Table 1). The strengthened beams failed by the intermediate crack debonding (ICD) of the CFRP profiles and splitting of the concrete cover surrounding the CFRPs (CCS) (Fig. 4). This failure initiated by flexural cracking in the concrete cover within the maximum bending moment region (the region of the innermost loads). During the loading process when the width of this crack increased, it slightly changed towards the horizontal inclination, developing from the mid-span to one of the supports, which was followed by an abrupt debonding of the CFRP profile and separating the attached concrete cover at the level of the longitudinal steel reinforcement. In other words, the failure was always initiated in the pure bending moment zone and propagated towards one of the supports (Fig. 4). One of the strengthened beams (1T-15) partially failed by a mixed mode of failure: the pure interfacial bond between the CFRP profile and adhesive (bond profile-adhesive, BPA) and the intermediate crack debonding (ICD). This failure was caused by a deficient adhesion between the smooth CFRP profile and adhesive. In the beam strengthened with two profiles of $15 \mathrm{~mm}$ web height, a detached concrete cover consisted of a concrete triangular prism with the CFRP profile inside. The longitudinal crack formed along the web of the CFRP profile was observed in the beams strengthened with T-30 
profiles (1T-30 and 2T-30), whose propagation conducted to the longitudinal fracture of the profile's web (LFP) at the failure of the corresponding beam (Fig. 4). This type of failure mode in the CFRP was already observed in conventional rectangular cross section CFRP laminates [7]. Moreover, application of two T profiles led to the separation of a large concrete cover (CCS), completely exposing the tensile and shear reinforcement, which was especially intense when using T-30 profiles, due to the larger stiffness of these CFRP systems and eventual group effect (Fig. 4). On the other hand, cutting the steel stirrups during the installation of the T-30 profiles did not have a significant impact on the behavior of the strengthened elements, as already demonstrated by Kotynia (2006) and Costa and Barros (2010) [7, 17].

The strengthening efficiency in terms of ultimate load, by considering $\eta_{f}$ ratio, has ranged from $114.6 \%$ (for the 1T15 beam) up to $252.1 \%$ (for the $2 \mathrm{~T}-30$ beam). In this regard, although the beam strengthened with two T- 15 profiles (2T-15) had a higher CFRP reinforcement ratio than the beam strengthened with one T-30 profile (1T-30), the 1T-30 beam presented a higher $\eta_{f}(172.1 \%)$ than the $2 \mathrm{~T}-15$ beam (166.7\%). As it was expected, the highest strengthening ratio was obtained for the beam strengthened with two CFRP T-30 profiles (2T-30) with a gain $79.2 \%$ higher than for the 1T-30 beam strengthened with only one T-30 profile.

\section{NUMERICAL SIMULATION}

\subsection{Description of finite element model}

Previous research of the authors [26] evidenced that, a 3D finite element (FE) approach, capable of simulating the nonlinear behavior of the used materials and the CFRP-epoxy adhesive and concrete-epoxy adhesive interfaces, can predict with high accuracy the behavior of RC structures strengthened with CFRP reinforcement. Hence, this numerical approach was used to simulate the experimental tests, by modelling one quarter of the beam, taking advantage of the double symmetry of the beams in order to reduce the computational time (Fig. 5).

Eight-node 3D solid elements were adopted to model the concrete, CFRP profile and epoxy adhesive, while 3D twonode truss elements were embedded into the concrete elements to simulate the behavior of steel reinforcements (Fig. 5b). Fig. 5a represents the finite element mesh of the $2 \mathrm{~T}-30$ beam, where a refined mesh was applied in the location 
where relatively high strain gradients are expected to develop. The support and loading conditions were simulated according to the characteristics of the test setup, as represented in Fig. $5 b$.

Concrete Damaged Plasticity (CDP) model was adopted to simulate the concrete's nonlinear behavior. In the CDP model, the concepts of linear isotropic elasticity in combination with isotropic tensile and compressive plasticity are used to simulate the inelastic behavior of concrete. The CDP model considers two main damage mechanisms of the concrete, namely: cracking formation and propagation in tension; and elasto-plasticity in compression [27]. The constitutive parameters of the CDP model (dilation angle $\psi$, plastic potential eccentricity $e$, stress ratio $f_{b 0} / f_{c 0}$ (ratio between the compressive strength in bi- and uni-compression stress field, $f_{b 0}$ and $f_{c 0}$, respectively), shape of the loading surface $K_{c}$, and viscosity parameter $V$ ) were estimated based on the recommended range of values by [27, 28]. In fact, the parameters $\psi$ and $e$ represent the shape of the flow potential function, while $f_{b 0} / f_{c 0}$ and $K_{c}$ describe the shape of the yield function and the adopted values for these two parameters are the recommended default ones [27, 29]. For normal concrete materials, dilation angle $(\psi)$ and flow potential eccentricity $(e)$ can be physically estimated equal to concrete internal friction angle and ratio between tensile and compressive strength of concrete, respectively [28]. Hence, $\psi$ parameter usually ranges between $36^{\circ}$ and $40^{\circ}$, and 0.1 is the value recommended by the CDP model for $e$ parameter. The value of $V$ parameter was assumed to be zero in this analysis.

In the present research, the uniaxial behavior of the uncracked concrete in tension and compression was assumed to be linear up to $f_{c t}$ (concrete tensile strength) and $0.45 f_{c c}$ (concrete compressive strength), respectively (Fig. 6a) [30, 31]. The concrete nonlinear stress-strain relation for uniaxial compression was obtained according to the recommendations of CEB-FIP model code [31]. Besides, to take into account the residual tensile stresses due to shrinkage, the in-situ tensile strength of the concrete was adopted as $f_{c t}=0.3 \sqrt{f_{c c}}$ [32]. Moreover, to describe the concrete tensile post-cracking behavior, a stress-crack opening relation according to CEB-FIP model code [31], represented in Fig. 6b, was used for the cracked concrete (using concrete tensile fracture energy, $G_{f}$, recommended by [27]). In this regard, the CDP model uses the concept of concrete crack bandwidth considering a characteristic length associated with an integration point [27]. This characteristic length is based on the element geometry using a line across the element (element length). In other words, for solid element, it is obtained by the cubic root of the element volume. 
An idealized elasto-plastic model with associated plastic flow was assigned to the truss elements to simulate the behavior of the steel bars up to its ultimate tensile strength (after this point its resisting tensile strength is neglected) based on the simplified model recommended by CEB-FIP code [31] (Fig. 6c). The elasto-perfectly plastic stress-strain diagram represented in Fig. 6c was used to simulate the tensile behavior of the epoxy adhesive. The tensile behavior of the CFRP profiles was assumed to be linear up to its ultimate tensile strength, as represented in Fig. 6d. After ultimate tensile strain, $\varepsilon_{f u}$, the contribution of the CFRP profiles is neglected.

In the current study, to simulate the bond behavior of the CFRP profile-adhesive-concrete connections, two surfacebased contact interfaces were defined. One was used at the CFRP profile-epoxy adhesive interface, while the other was applied at the concrete-epoxy adhesive interface (Fig. 5c). A mixed mode of debonding including stress-separation (in the normal direction to the interface element plane) and shear stress-slip (on both directions of the interface element plane) was used to simulate the concrete-epoxy adhesive interface, while for the CFRP profile-epoxy adhesive interface only the shear stress-slip, in both directions of the plane, was considered. The governed laws for the damage evaluation of the interfaces were defined by a linear softening branch considering the fracture energy of the interfaces (Figs. 6e and 6f).

The normal tensile stress $\left(\sigma_{n, \max }\right)$ and tensile fracture energy $\left(G_{n, f}\right)$ of the concrete-epoxy adhesive interface was limited to the tensile strength and fracture energy of the concrete, while the maximum shear stress $\left(\tau_{s, \max }\right)$ and shear fracture energy $\left(G_{s, f}\right)$ of this bond was obtained from the model recommended by [33]. The maximum shear stress ( $\tau_{s, \max }$ ) of the CFRP profile-epoxy adhesive interface was found from the literature [34], while the shear fracture energy

$\left(G_{s, f}\right)$ corresponding to this interface was estimated by calculating the area under the proposed shear stress-slip curve [34].

\subsection{Assessment of the Predictive Performance of the Numerical Strategy}

To assess the predictive performance of the described numerical model, the obtained load versus mid-span deflection responses are compared in Fig. 7 with the corresponding ones registered experimentally. The adopted values for the 
numerical simulation of the tested beams, in terms of strength characteristic of concrete, CDP parameters, and interface properties are represented in Table 2.

The prevailing failure modes of the beams at the maximum load carrying capacity were numerically predicted similar to the ones experienced experimentally. In other words, after the yielding of the tensile steel bars, crushing of the concrete in the compression zone was numerically observed in the Ref beam, while almost all strengthened beams failed by splitting of the concrete cover (CCS) after initiation of intermediate crack debonding (ICD) in the maximum bending moment zone, and debond failure in the 1T-15 beam.

Fig. 7 indicates a good predictive performance of the numerical strategy in terms of the flexural response of the tested beams, with relatively small deviations on the prediction of the maximum load carrying capacity and its corresponding deflection. These deviations can be attributed to the use of embedded truss elements within the concrete elements to model the longitudinal tensile steel bars in the numerical model, preventing to create the weak plane in the concrete microstructure just below the tensile steel bars due to the existence of a higher percentage of voids at this level after concrete casting $[6,35]$. In fact, the concrete weak plane causes a boundary limit for the concrete cover surrounding the CFRP profile resisting to the susceptibility of occurring the tensile concrete cover splitting failure mode. On the other side, the influence of this concrete weak plane on the possibility of occurring the splitting failure can be more effective when the distance between the centroidal axis of the CFRP profile and concrete weak plane decreases ( $d$ in Fig. 8), which can occur by using a higher height of CFRP profile. This fact was moreover observed experimentally in the case of the application of T-30 CFRP profiles, where the 1T-30 and 2T-30 beams failed by separating a larger concrete cover, completely exposing the tensile and shear reinforcement, compared to the amount of concrete that remained attached to the T-15 profiles in the T-15 beams (see section TEST RESULTS). Accordingly, the numerical model has, in general, predicted higher load carrying capacity than the experimental one for the beams strengthened with T-30 CFRP profiles.

The concrete tensile strain field based on the PEEQT (equivalent plastic strain in uniaxial tension), PE33 (plastic strain in the direction of axis 3), and PE22 (plastic strain in the direction of axis 2) output of the FE software is represented in Fig. 9a for the 2T-30 beam at the maximum capacity. This figure evidences the occurrence of ICD and CCS failure modes captured by the development of the maximum concrete tensile strain gradient in the zones where experimentally 
these failure modes were observed, as evidenced by comparing with the corresponding experimental crack pattern in Fig. 9b.

A good predictive performance of the numerical simulation in terms of tensile strains recorded in the CFRP profile, as well as, concrete compressive strain monitored at the level of the longitudinal steel bars at mid-span cross section, is also evidenced in Fig. 10, where the corresponding values for the 1T-15 and 2T-30 beams are considered for the comparison purposes.

\section{PARAMERTIC STUDIES}

The current section aims to numerically evaluate the influence of the material properties and bond contact area of the used CFRP profile on the flexural response of the strengthened RC beams by using the described FE model. The analyzed parameters of the material properties were the elasticity modulus of CFRP reinforcement and strength characteristic of concrete. Moreover, CFRP profiles with different bond contact area and similar cross sectional area were adopted to numerically strengthen $\mathrm{RC}$ beams, in order to evaluate the influence of the CFRP contact area on the strengthening performance.

\subsection{Material Properties}

Fig. 11a shows the influence of the elasticity modulus of CFRP profile on the numerical flexural response of the 2T$30 \mathrm{RC}$ beam in terms of load versus mid-span deflection. For the comparison purposes, the elasticity modulus of 120 $\mathrm{GPa}$ and $180 \mathrm{GPa}$ was adopted for the CFRP profiles, which are almost 0.8 and 1.2 times the CFRP elasticity modulus adopted in the experimental program (149 GPa), respectively. It should be noted that the lower limit of the CFRP elasticity modulus $(120 \mathrm{GPa})$ was adopted according to the recommendation of ACI-440.1R. Fig. 11a evidences that the higher elasticity modulus of the CFRP profile decreased the ultimate deflection capacity of the strengthened beams, while it had no effect on the prevailing failure mode at the ultimate stage (all the three beams failed by CCS). In fact, by increasing the CFRP elasticity modulus, the flexural stiffness of the strengthened beams increases, which is more noticeable after the yielding of the tensile steel reinforcement (the postyielding phase of the flexural response). 
On the other hand, in order to evaluate the influence of the strength characteristic of concrete on the flexural response of the strengthened RC beams, in Fig. 11b, the numerical flexural response of the 2T-30 beam in terms of load versus mid-span deflection was compared to the corresponding responses of the RC beams strengthened using 2T-30 CFRP profiles with concrete compressive strength ( $f_{c c}$ ) of $20 \mathrm{MPa}$ and $40 \mathrm{MPa}$. By adopting different concrete compressive strength, the relevant parameters of the FE models in terms of the elasticity modulus and tensile strength of the concrete, as well as the properties of the concrete-epoxy adhesive interface, were modified for the analyzed beams (see Table 3). Fig. 11b shows that by adopting a lower concrete strength, a decrease in terms of the ultimate load carrying and deflection capacity was obtained for the strengthened beams. Since all these three strengthened beams failed by CCS mode at the maximum capacity, it can be concluded that a lower concrete strength decreased the resistance to the susceptibility of occurring the tensile concrete cover splitting failure.

\subsection{Bond Contact Area of the CFRP Profiles}

The objective of this section is to numerically evaluate the influence of the bond contact area of the CFRP profiles, used in the experimental program, on the susceptibility of occurring the tensile concrete cover splitting failure mode, which was observed experimentally and numerically at the ultimate stage of the strengthened beams. For this purpose, the T-Sec.B CFRP profile, represented in Fig. 12, was adopted for the flexural strengthening of RC beams with the aim of providing a cross sectional area and bond contact area equal to the T-15 (Sec.A in Fig. 12) and T-30 (Sec.C in Fig. 12) CFRP profiles used in the experimental program, respectively. Besides, the CFRP profile of Sec.D in Fig. 12 was adopted to have a cross sectional area similar to the T-30 CFRP profile with a bond contact area equal to the T15 CFRP profile.

Figs. 12a and $12 \mathrm{~b}$ compare numerically the flexural responses of the $1 \mathrm{~T}-15$ and $2 \mathrm{~T}-15$ beams with the corresponding responses of the RC beams strengthened with 1T-Sec.B and 2T-Sec.B CFRP profiles, respectively. Besides, the flexural responses of the 1T-30 and 2T-30 beams are compared in Figs. 12c and 12d with the corresponding responses obtained by the RC beams strengthened with 1T-Sec.D and 2T-Sec.D CFRP profiles, respectively. In other words, the numerical flexural response of each strengthened beam, adopted in the experimental program, was compared in Fig. 12 to the corresponding response of the RC beam strengthened with a CFRP profile with similar cross sectional area 
and different bond contact area. This figure, moreover, represents a comparison between the cross sectional area $\left(A_{f}\right.$ ), bond contact area $\left(A_{b}\right)$, and ratio between bond area and cross sectional area $\left(A_{b} / A_{f}\right)$ of the adopted CFRP profiles in the current analysis. Fig. 12 evidences that the RC beams strengthened with T-Sec.B CFRP profile (Figs. 12a and 12b) provided a higher ultimate load carrying and deflection capacity when compared to the corresponding terms of the RC beams strengthened with T-Sec.A CFRP profile. This higher capacity can be attributed to a higher confinement provided by the surrounding concrete to the T-Sec.B CFRP profile due to its larger ratio of bond area to cross sectional area $\left(A_{b} / A_{f}=0.54\right)$ compared to the corresponding ratio of the T-Sec.A CFRP profile $\left(A_{b} / A_{f}=0.36\right.$ ), mainly the part embedded into the groove. In fact, the higher concrete confinement has postponed concrete cover splitting failure at the ultimate stage of the strengthened beams. The RC beams strengthened with T-Sec.B CFRP profile failed by the rupture of the CFRP profile in the maximum bending moment zone, while the T-Sec.A CFRP strengthened beams experienced the concrete cover splitting failure before occurring the rupture of the CFRP. On the other side, the RC beams strengthened with T-Sec.D CFRP profile (Figs. 12c and 12d) decreased the ultimate load carrying and deflection capacity when compared to the corresponding terms of the RC beams strengthened with T-Sec.C CFRP profile, due to its smaller ratio of bond area to cross sectional area, mainly the part embedded into the groove. Moreover, all the beams strengthened with T-Sec.C CFRP and T-Sec.D CFRP profiles failed by the concrete cover splitting at the ultimate stage.

\section{CONCLUSIONS}

The current work has explored the potentialities of the use of CFRP profiles for the flexural strengthening of RC beams by performing an experimental program and executing parametric studies with a 3D nonlinear finite element (FE) approach demonstrated capable of simulating with good accuracy the behavior of these type of structural systems.

From the experimental tests the following conclusions can be pointed out:

- The adopted CFRP profiles have significantly increased the load bearing capacity of RC members, having varied between $114.6 \%$ to $252.01 \%$ of the non-strengthened beam;

- By increasing the number of applied T-shaped profiles the maximum load and the beam's stiffness have increased, while the maximum strain level installed in these profiles has decreased. The maximum strain in the CFRP profiles 
and the load carrying capacity have increased with the web depth of these profiles. In fact, in the profiles with higher web depth (T30) maximum strains of $0.69 \%$ and $0.92 \%$ were registered for strengthening with two and one $\mathrm{T}$ profiles, respectively, while in the T15 profiles these strains were, accordingly, $0.61 \%$ and $78 \%$;

- The intermediate crack debonding with adjacent concrete cover splitting was the most common failure mode;

- Cutting the bottom arm of the steel stirrups for the installation of the CFRP profiles did not affect the ultimate load and the beams deformability.

From the numerical simulations and parametric studies the following remarks can be highlighted:

- A developed 3D FE model was used to simulate the experimental program composed of RC beams strengthened with CFRP profiles. This model is capable of simulating the nonlinear behavior of the constituent materials and both CFRP profile-epoxy adhesive and concrete-epoxy adhesive interfaces;

- The good predictive performance of the FE model in terms of the flexural response of RC beams strengthened with CFRP profiles was demonstrated. Moreover, the prevailing failure modes of the strengthened beams at the maximum load carrying capacity were numerically predicted similar to the ones experienced experimentally (splitting of the tensile concrete cover (CCS) after initiation of intermediate crack debonding (ICD) in the maximum bending moment zone). From the observed results, it can be concluded that the nonlinear FE model proposed herein provides researchers and designers a computational tool with good accuracy for design of FRP strengthened beams when failing by conventional flexural failure or premature failure modes (like splitting of the concrete cover or FRP debonding failure modes). Hence, using the proposed FE model, it is possible to do trial and error to optimize the efficiency of these types of FRP techniques for the flexural strengthening of RC structures before their real application;

- From the numerical parametric studies, it was verified that by increasing the elasticity modulus of the CFRP profiles, a higher flexural stiffness (noticeably in the postyielding phase of the flexural response) and load carrying capacity at the steel yield initiation is obtained for the RC beams strengthened with CFRP profiles, while the opposite occurs with the decrease of the CFRP elasticity modulus. Moreover, the elasticity modulus of the CFRP profiles had no effect on the resistance to susceptibility of concrete cover splitting failure mode, since all the strengthened beams with different CFRP elasticity modulus provided similar maximum flexural capacity and failed by concrete cover 
splitting failure mode. Accordingly, a higher flexural stiffness of the strengthened beams due to the use of a higher CFRP elasticity modulus, caused a reduction in terms of the ultimate deflection capacity of the strengthened beams;

- The obtained results showed that by adopting a lower strength characteristic of concrete in terms of its compressive and tensile strengths and properties of concrete-epoxy adhesive interface, a lower resistance to the susceptibility of occurring the tensile concrete cover splitting failure is obtained for the strengthened beams, resulting in a decrease in terms of the ultimate load carrying and deflection capacity;

- A higher ratio of bond area and cross sectional area of the CFRP profiles $\left(A_{b} / A_{f}\right)$ provided a higher resistance to the susceptibility of occurring the tensile concrete cover splitting failure, due to a higher confinement provided by the surrounding concrete to the CFRP profile. This higher resistance to the concrete cover splitting failure caused a higher load carrying and deflection capacity of the RC beams strengthened with CFRP profiles. Hence, for design (strengthening) purposes, in order to provide a higher resistance to the concrete cover splitting failure (which is a premature failure mode before conventional flexural failure modes of the strengthened beams), $A_{b} / A_{f}$ ratio of the CFRP profile should be maximized.

\section{ACKNOWLEDGMENT}

The first and the last authors acknowledge the support provided by Cutinov QREN project $\mathrm{n}$. 38780 supported by ADI, co-financed by the European Regional Development Fund (FEDER) through the Operational Program COMPETE. The second and the third authors would like to acknowledge the support provided by Mostostal Warszawa S.A. for providing the CFRP T-shaped profiles and for co-funding the research program.

\section{NOTATIONS}

$A_{f} \quad: \quad$ Cross sectional area of the CFRP profile, $\mathrm{mm}^{2}$;

$A_{b} \quad: \quad$ Bond contact area of the CFRP profile, $\mathrm{mm}^{2}$;

e $\quad:$ Plastic potential eccentricity; 
$E_{c} \quad: \quad$ Elasticity modulus of concrete, GPa;

$E_{f} \quad ; \quad$ Elasticity modulus of CFRP reinforcement, GPa;

$E_{s} \quad ; \quad$ Elasticity modulus of steel reinforcement, GPa;

$f_{b 0} \quad ; \quad$ Concrete compressive strength in bi-compression stress field, MPa;

$f_{c 0} \quad: \quad$ Concrete compressive strength in uni-compression stress field, MPa;

$f_{c c} \quad: \quad$ Compressive strength of concrete, $\mathrm{MPa}$;

$f_{c t} \quad: \quad$ Tensile strength of concrete, MPa;

$f_{f u} \quad: \quad$ Tensile strength of CFRP reinforcement, $\mathrm{MPa}$;

$f_{s y} \quad: \quad$ Yielding strength of steel reinforcement, MPa;

$f_{s u} \quad: \quad$ Ultimate strength of steel reinforcement, MPa;

$G_{f} \quad:$ Concrete tensile fracture energy, N/mm;

$G_{n, f} \quad: \quad$ Tensile fracture energy of the interface, $\mathrm{N} / \mathrm{mm}$;

$G_{s, f} \quad: \quad$ Shear fracture energy of the interface, $\mathrm{N} / \mathrm{mm}$;

$K_{c} \quad: \quad$ Shape of the loading surface;

PEEQT : Equivalent plastic strain in uniaxial tension;

PE22 : Plastic strain in the direction of axis 2;

PE33 : Plastic strain in the direction of axis 3;

V $\quad$ : Viscosity parameter;

$\varsigma_{f} \quad: \quad$ CFRP reinforcement ratio;

$\varepsilon_{f, \text { flange }}:$ CFRP tensile strains in the flange, $\mathrm{mm} / \mathrm{mm}$;

$\varepsilon_{f u} \quad: \quad$ CFRP ultimate tensile strain, $\mathrm{mm} / \mathrm{mm}$;

$\varepsilon_{f, w e b}:$ CFRP tensile strains in the web, $\mathrm{mm} / \mathrm{mm}$;

$\psi \quad$ : Dilation angle in CDP model; 


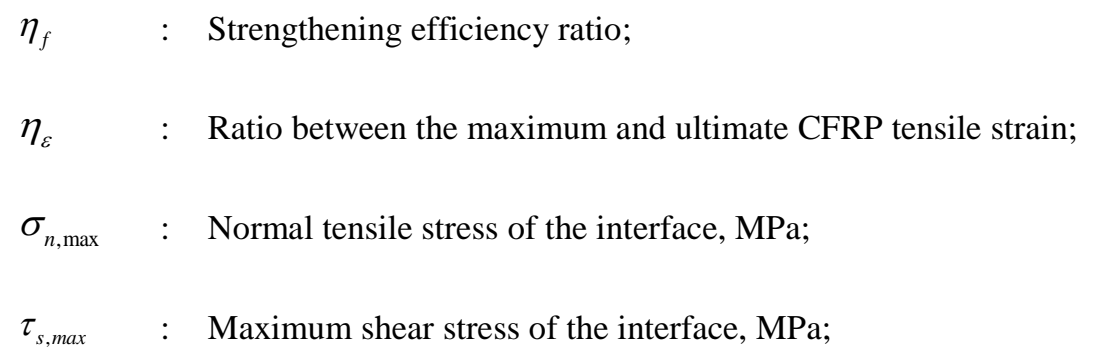

\section{REFERENCES}

1. ACI-440. (2002). Guide for the design and construction of externally bonded FRP systems for strengthening concrete structures, American Concrete Institute (ACI) Committee 440, 118.

2. Fib - Bulletin 14. (2001). Externally bonded FRP reinforcement for RC structures, Technical report by Task, Group 9.3 FRP, 130.

3. CNR DT 200 (2004). Guide for the Design and Construction of Externally Bonded FRP Systems for Strengthening Existing Structures, National Research Council, Advisory Committee on Technical Recommendations for Construction.

4. Capozucca, R. (2009). Static and Dynamic Response of Damaged RC Beams Strengthened with NSM CFRP Rods, Composite Structures, 91, 237-248.

5. ACI-440.2R. (2008). Guide for the Design and Construction of Externally Bonded FRP Systems for Strengthening Concrete Structures, American Concrete Institute (ACI) Committee 440.

6. Barros, J., Kotynia, R. (2008). Possibilities and challenges of NSM for the flexural strengthening of RC structures, Proc. of Fourth International Conference on FRP Composites in Civil Engineering CICE2008, Zurich, Switzerland.

7. Costa, I., Barros, J. (2010). Flexural and shear strengthening of RC beams with composites materials - the influence of cutting steel stirrups to install CFRP strips, Cement and Concrete Composites Journal, 32, 544-553.

8. Costa, I., Barros, J. (2013). Critical analysis of fibre-reinforced polymer near-surface mounted double-shear pullout tests, Strain - An International Journal for Experimental Mechanics, 49, 299-312. 
9. De Lorenzis, L., Nanni, A., La Tegola, A. (2000). Flexural and shear strengthening of reinforced concrete structures with near surface mounted FRP rods, In: Humar J, Razaqpur AG, editors, Proceedings of the third international conference on advanced composite materials in bridges and structures, Ottawa, Canada, pp 521-528.

10. Bonaldo, E., Barros, J., Lourenço, P. (2008). Efficient strengthening technique to increase the flexural resistance of existing RC slabs, Composites for Construction Journal (ASCE), 12(2), 149-159.

11. Taljsten, B., Carolin, A., Nordin, H. (2003). Concrete structures strengthened with near surface mounted reinforcement of CFRP, Advances in Structural Engineering, 6(3), 201-13.

12. Rezazadeh, M., Costa, I., Barros, J. (2014). Influence of Prestress Level on NSM CFRP Laminates for the Flexural Strengthening of RC Beams, Composite Structures, 116:489-500.

13.Parretti, R., Nanni, A. (2004). Strengthening of RC members using near-surface mounted FRP composites: design overview, Advances in Structural Engineering, 7(6), 469-83.

14.El-Hacha, R., Rizkalla, S. (2004). Near-surface-mounted fiber-reinforced polymer reinforcements for flexural strengthening of concrete structures, ACI Structural Journal, v 101 n 5, 717-726.

15.Hassan, T., Rizkalla, S. (2004). Bond mechanism of near-surface-mounted fiber reinforced polymer bars for flexural strengthening of concrete structures, ACI Structural Journal, 101(6), 830-9.

16. Rezazadeh, M. Barros, J. (2014). A New Hybrid Methodology According to Near Surface Mounted Carbon Fiber Reinforced Polymer Technique for the Flexural Strengthening of Reinforced Concrete Beams, Reinforced Plastics and Composites, 33(21):1993-2009.

17. Kotynia, R. (2006). Analysis of reinforced concrete beams strengthened with near surface mounted FRP reinforcement, Archives of civil and mechanical engineering, LII 2., 305-317.

18. Kotynia, R. (2012). Bond between FRP and concrete in reinforced concrete beams strengthened with near surface mounted and externally bonded reinforcement. Construction and Building Materials, v 32, 41-54.

19. Barros, J., Varma, R., Sena-Cruz, J., Azevedo, A. (2008). Near Surface Mounted CFRP Strips for the Flexural Strengthening of RC Columns - Experimental and Numerical Study, Engineering Structures, 30(12): 3412-3425. 
20. Oudah, F., El-Hacha, R. (2011). Ductility of Reinforced Concrete Beams Strengthened using Prestressed NSM CFRP Strips/Rebars- Analytical Study, First Middle East Conference on Smart Monitoring, Dubai, UAE.

21. Radfar, S., Foret, G., Saeedi, N., Sab, K. (2012). Simulation of Concrete Cover Separation Failure in FRP Plated RC Beams, Construction and Building Materials, 73: 791-800.

22. Al-Mahmoud, F., Castel, A., François, R., Tourneur, C. (2010). RC beams strengthened with NSM CFRP rods and modeling of peeling-off failure, Composite Structures, 92; 1920-1930.

23. Omran, H., El-Hacha, R. (2011). Nonlinear 3D Finite Element Modeling of RC Beams Strengthened with Prestressed NSM-CFRP Strips, Construction and Building Materials, 74-85.

24. Hawileh, A. (2011). Nonlinear Finite Element Modeling of RC Beams Strengthened with NSM FRP Rods. Construction and Building Materials, Doi: 10.1016/j.conbuildmat.2011.07.018.

25. Kotynia, R., Cholostiakow, Sz. (2015). New Proposal For Flexural Strengthening of Reinforced Concrete Beams Using CFRP T-Shaped Profiles, Journal of Polymers, Doi: 10.3390/polym.

26. Rezazadeh, M. (2015). Innovative Methodologies for the Enhancement of the Flexural Strengthening Performance of NSM CFRP Technique for RC Beams, PhD Thesis, University of Minho, Portugal.

27. ABAQUS. (2011). Abaqus Analysis User’s Manual.

28. Kmiecik, P., Kaminski, M. (2011). Modeling of Reinforced Concrete Structures and Composite Structures with Concrete Strength Degradation Taken into Consideration, Archives of civil and mechanical engineering, Wroclaw University of Technology, No.3, Poland.

29. Jankowiak, T., Lodigowski, T. (2005). Identification of Parameters of Concrete Damage Plasticity Constitutive Model, Foundation of civil and environmental engineering, No. 6.

30. ACI 318-05. (2005). Building Code Requirements for Structural Concrete, ACI Committee 318.

31. CEB-FIP. (2011). Model Code 2010. Final draft fib, CEB-FIP. 
32. Amin, A., and Foster, Stephen. (2014). Numerical Modelling of Large Scale Steel Fibre Rein-forced-Reinforced Concrete Beams Failing in Shear, FRC 2014 Joint ACI-fib International Workshop Fibre Reinforced Concrete: from Design to Structural Applications.

33. Seracino, R., Saifulnaz, M., Oehlers, D. (2007). Generic Debonding Resistance of EB and NSM Plate-to-Concrete Joints, Journal of Composites for Construction (ASCE),11(1.).

34. Cruz, J., Barros, J. (2004). Modeling of Bond between Near Surface Mounted CFRP Laminate Strips and Concrete, Computers and Structures,1513-21.

35. Barros, J., Costa, I., Gouveia, A. (2011). CFRP Flexural and Shear Strengthening Technique for RC Beams: Experimental and Numerical Research, Advance in Structural Engineering, 14(3.). 


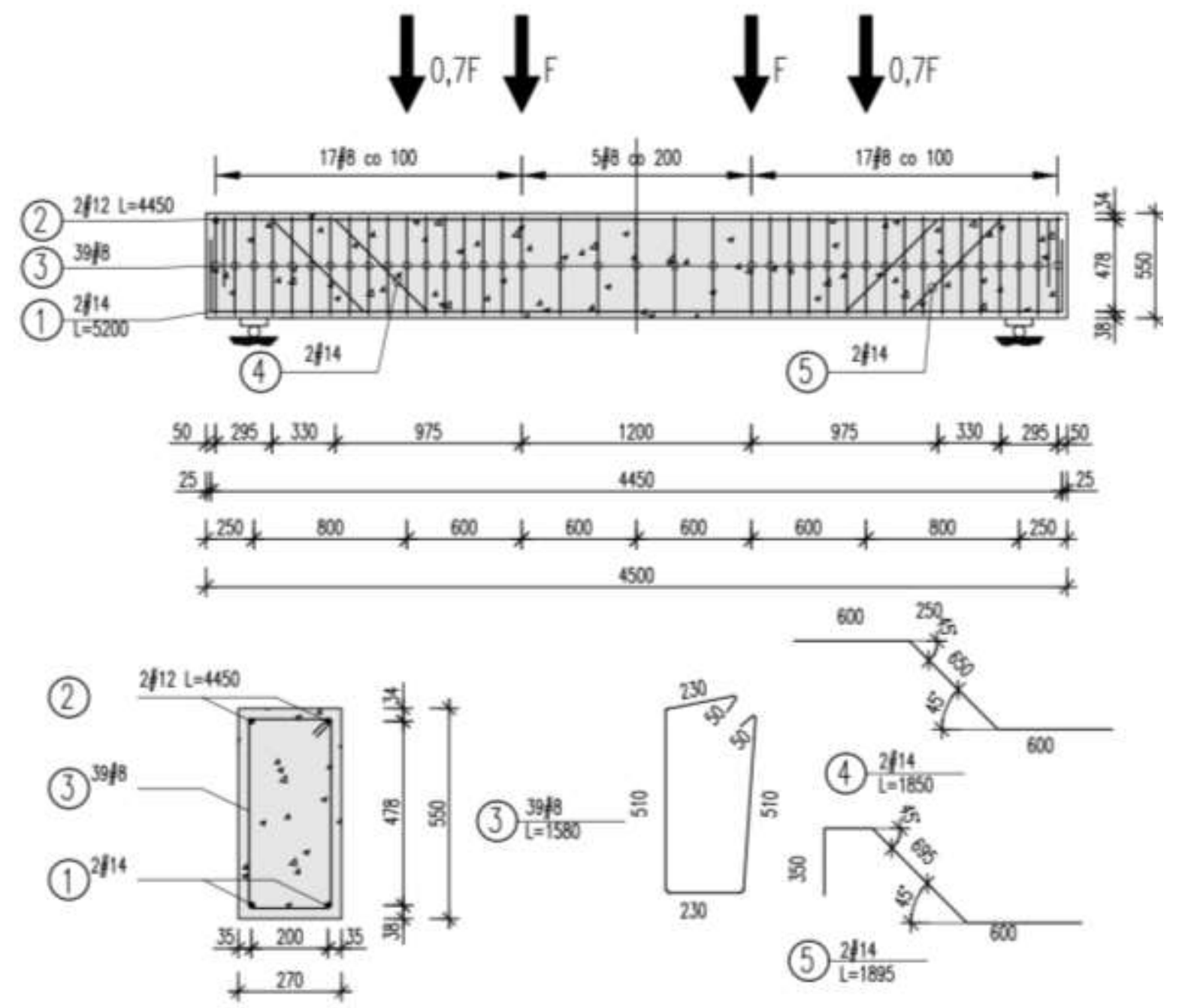

Fig. 1. Geometry, loading and support conditions, and steel reinforcement details of the tested beams (dimensions in $\mathrm{mm}$ ) 
a)

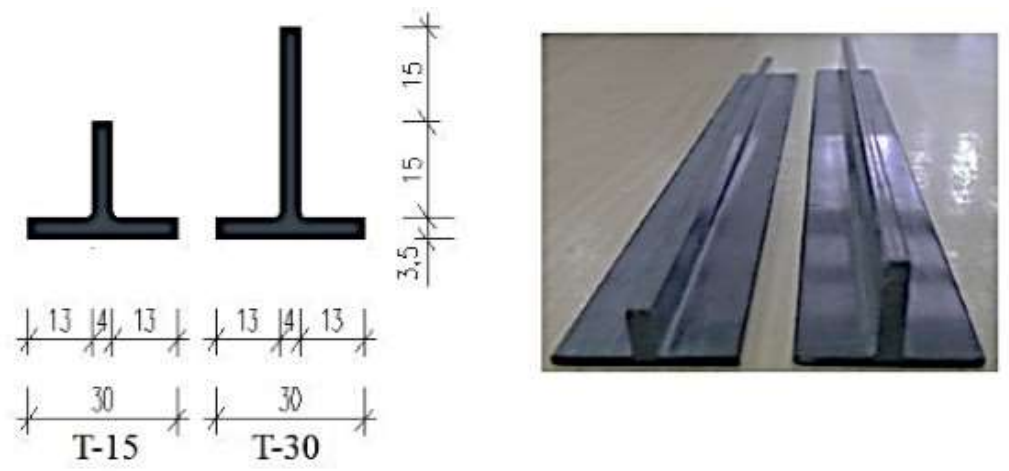

b)
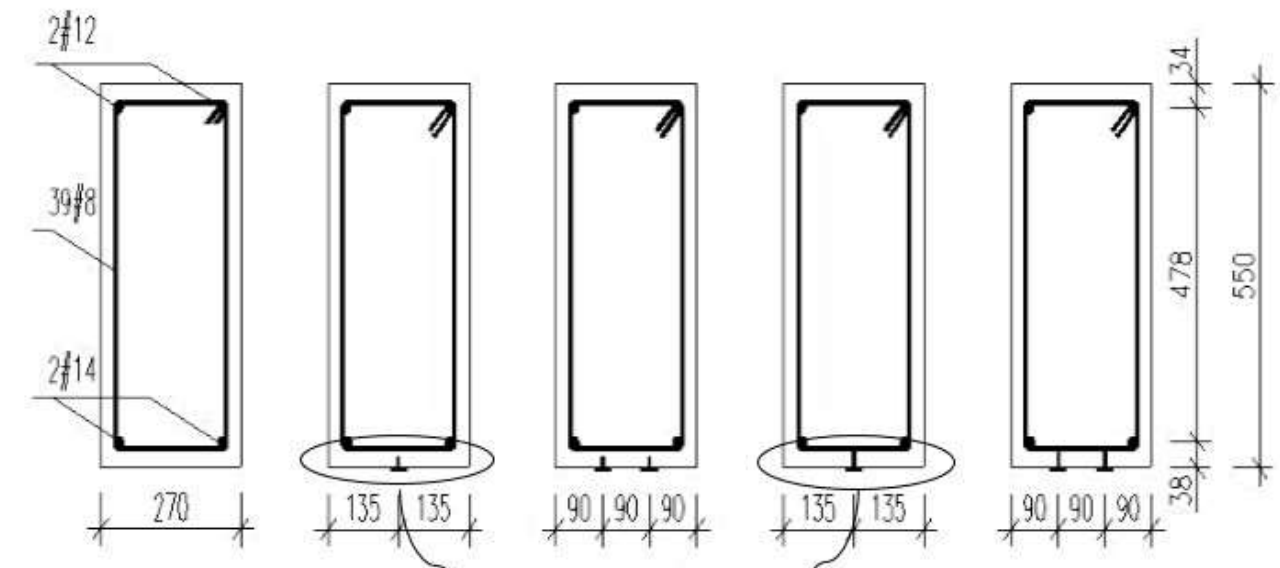

c)
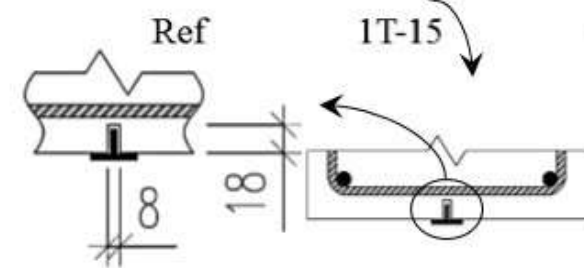

2T-15

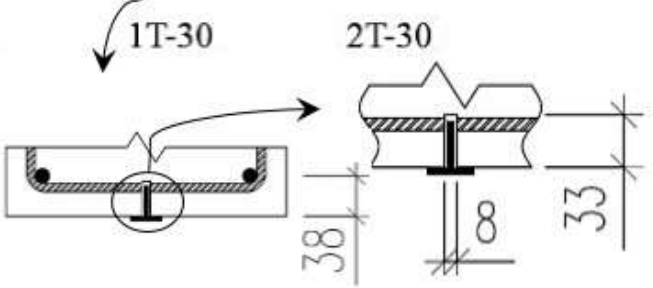

Fig. 2. a) Geometry of the CFRP profiles, b) cross-section and strengthening configurations of the beams, c) detail of the T-15 and T-30 profiles application (dimensions in $\mathrm{mm}$ ), 

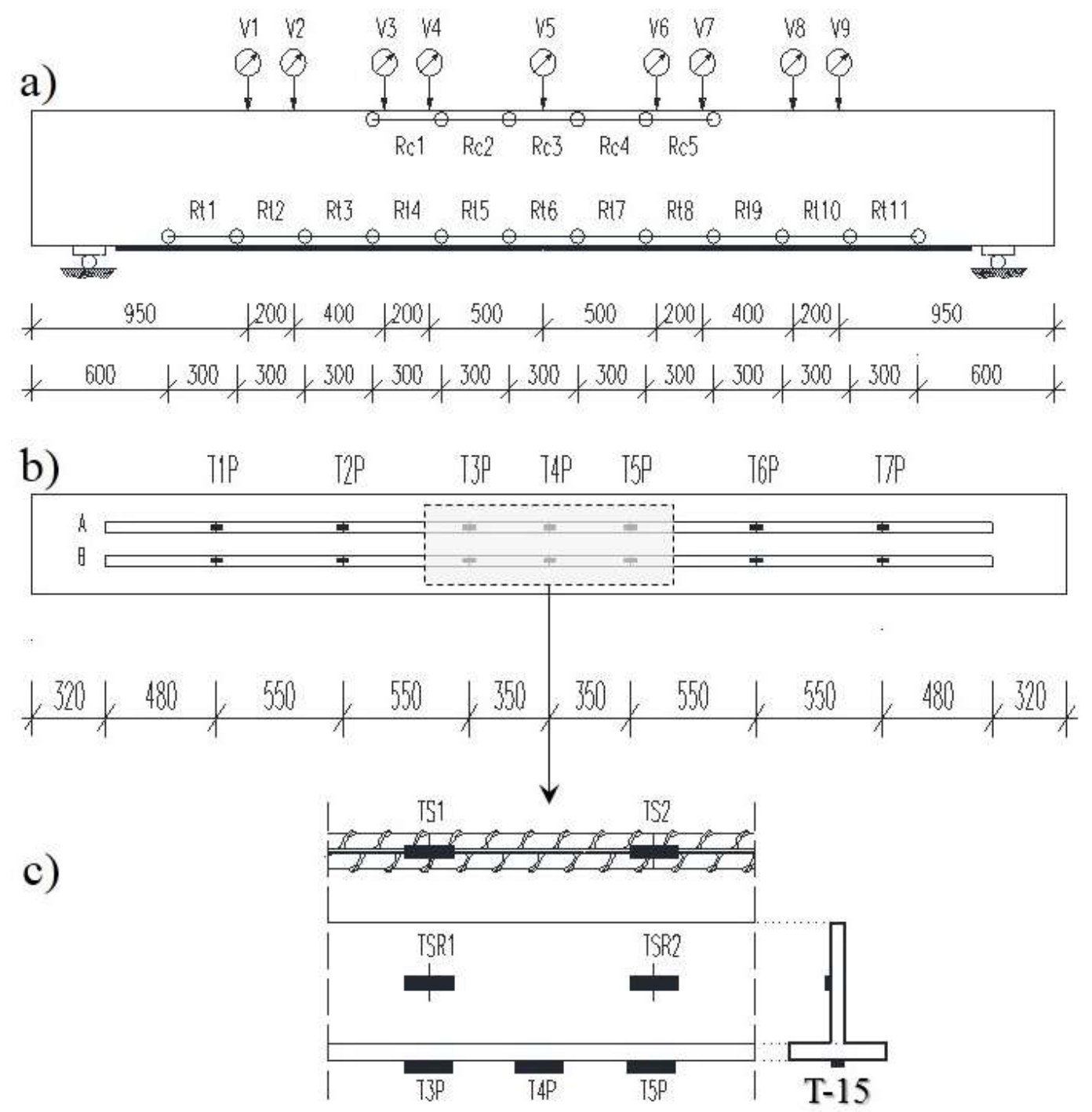

Fig. 3. a) Arrangement of the external LVDTs, b) location of the strain gauges along the flange of the CFRP profiles, c) location of strain gauges on the web of the CFRP profiles and on the internal steel reinforcement (dimensions in $\mathrm{mm}$ ) 


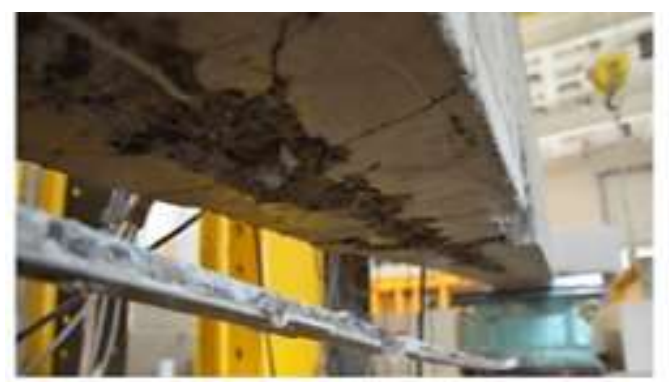

1T-15 beam

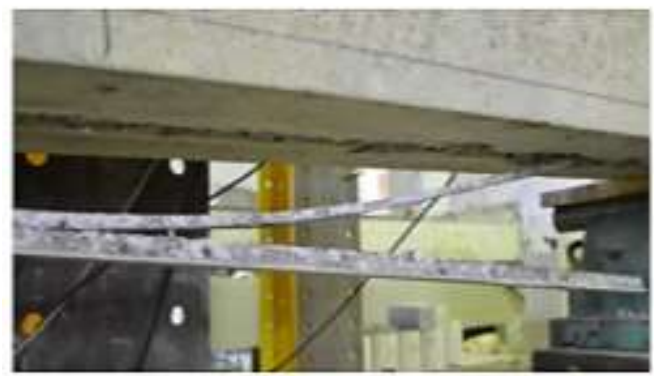

1T-30 beam

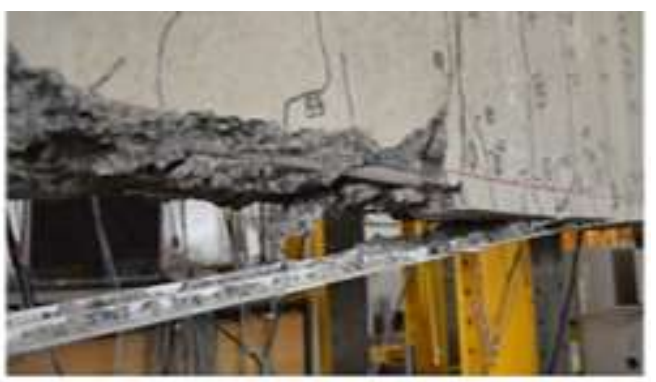

$2 \mathrm{~T}-15$ beam

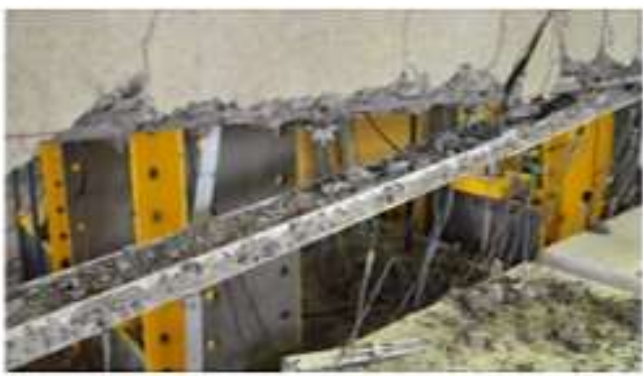

$2 \mathrm{~T}-30$ beam

Fig. 4. Failure modes of strengthened beams 
a)

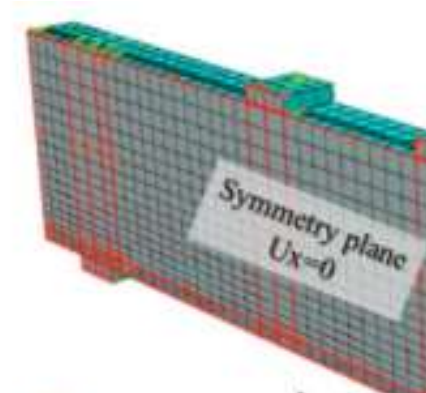

b)

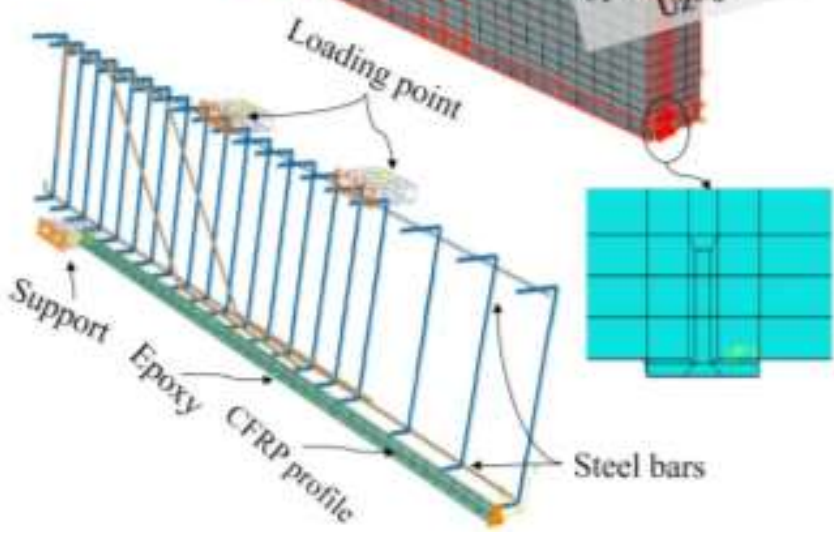

c)
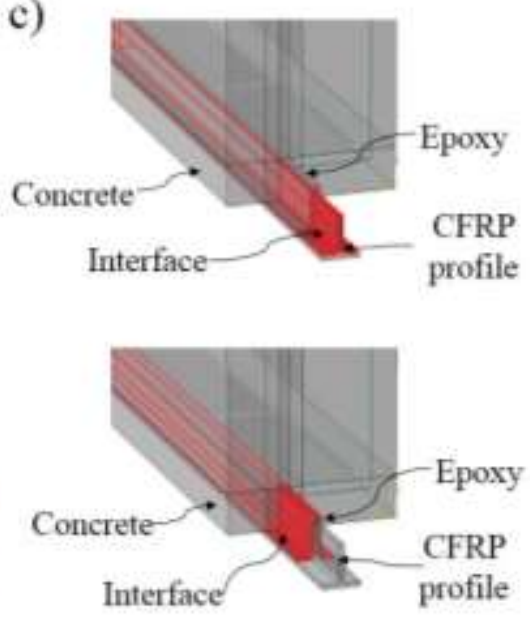

Fig. 5. a) Mesh of the FE model, b) boundary conditions and steel and CFRP reinforcements, c) interfaces between CFRP-epoxy and concrete-epoxy surfaces 

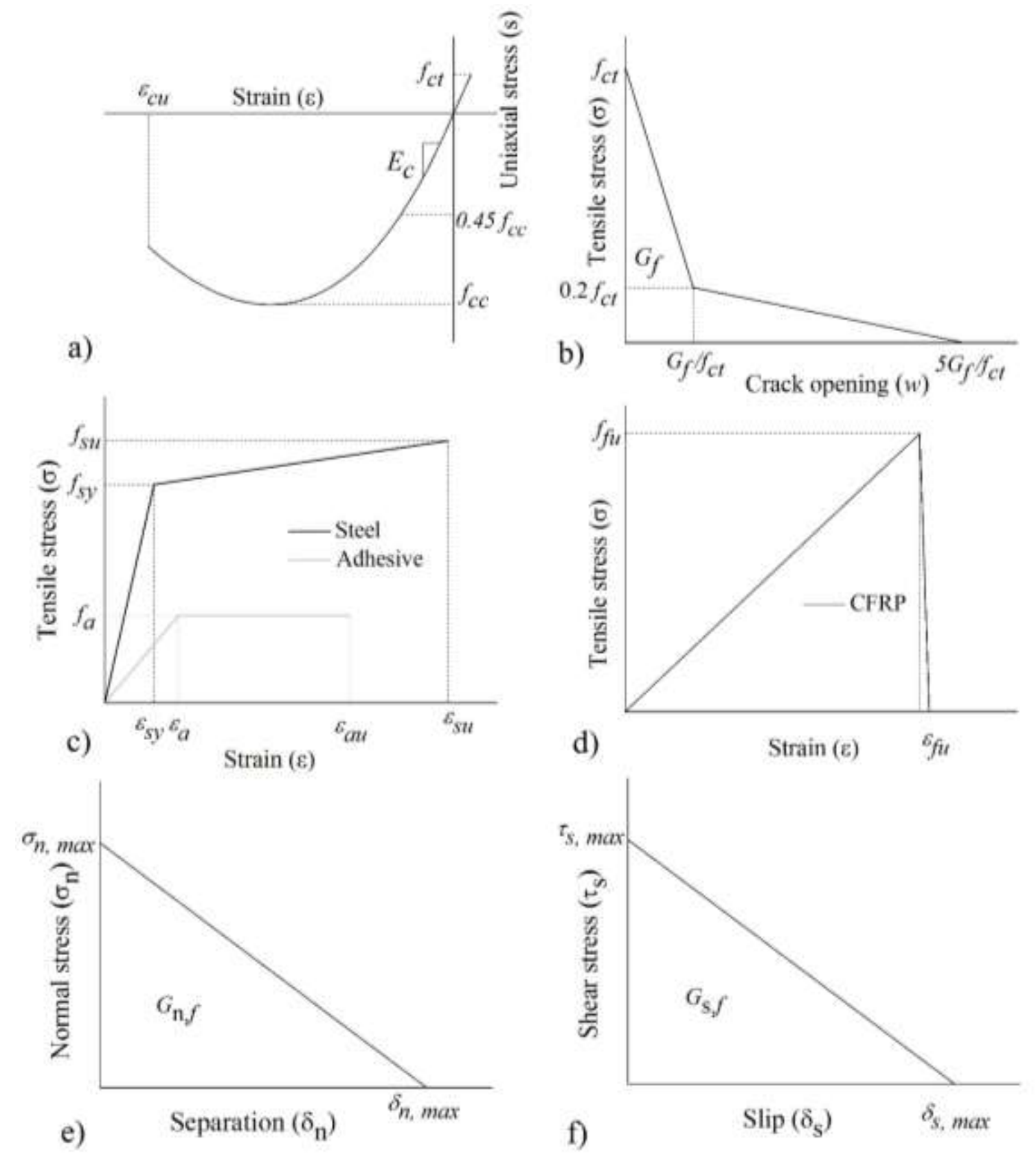

Fig. 6. Uniaxial constitutive laws of materials: a) concrete in compression and in tension up to crack initiation, b) concrete tensile post-cracking, c) steel reinforcement and epoxy adhesive, d) CFRP reinforcement, e) normal stressseparation relationship of the interface, f) shear stress-slip relationship of the interface 

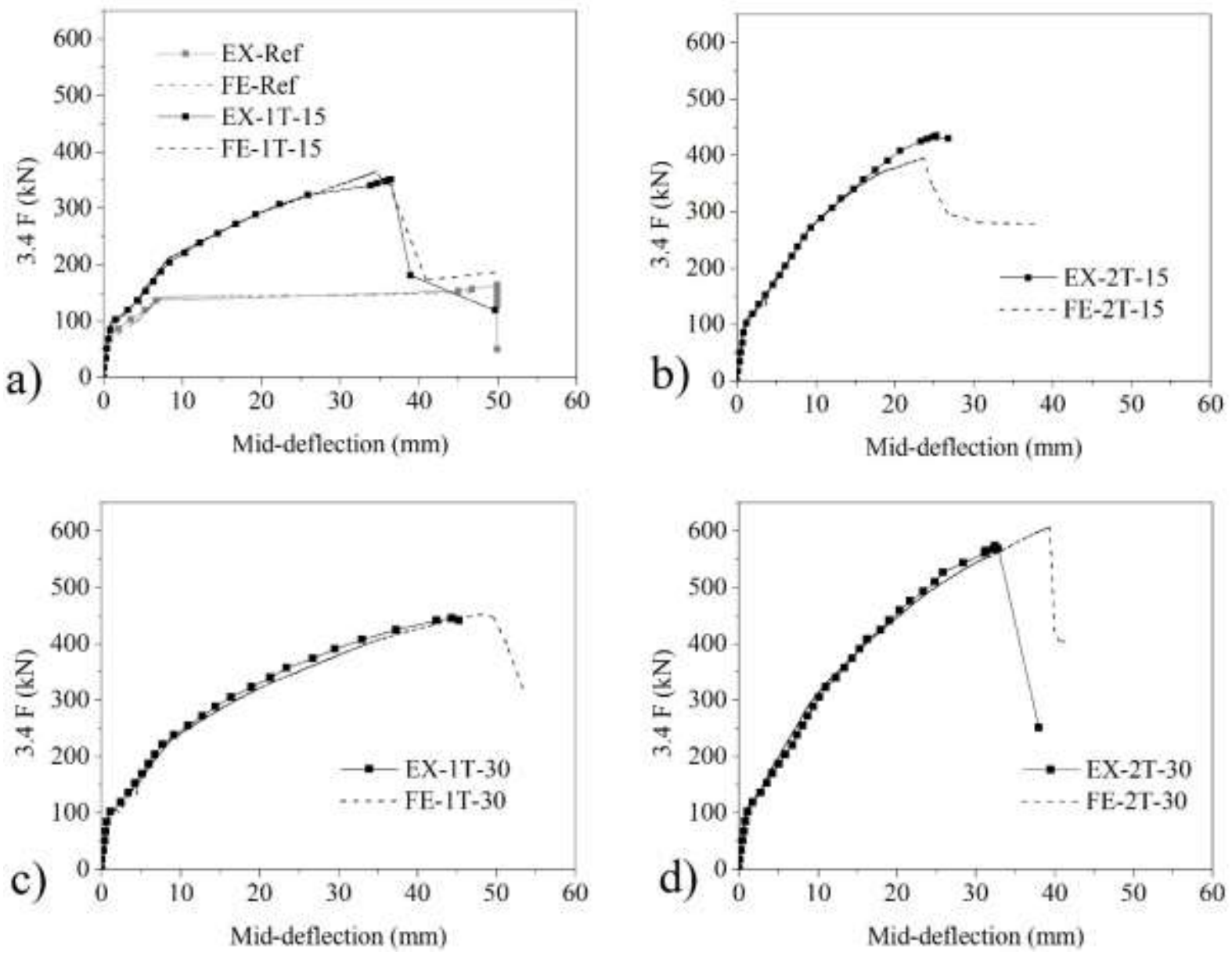

Fig. 7. Numerical simulation of the tested beams: a) Ref and 1T-15, b) 2T-15, c) 1T-30, and d) $2 \mathrm{~T}-30$ beam 


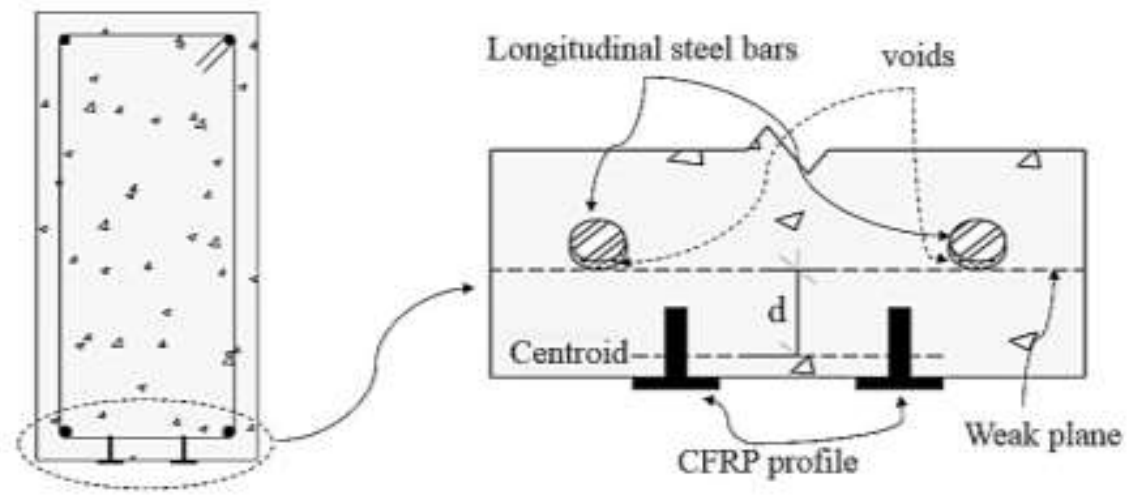

Fig. 8. Formation of concrete weak plane 
a)
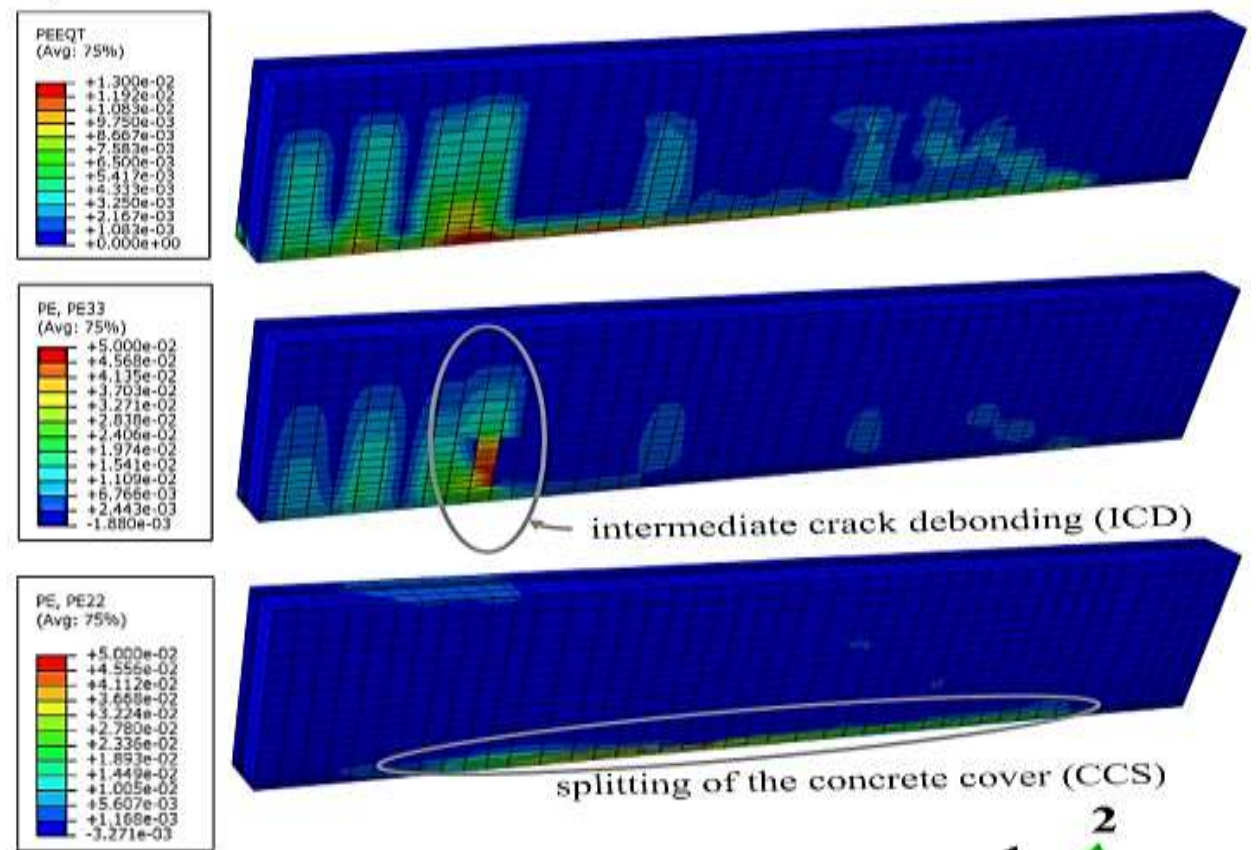

plitting of the concrete cover (CCS)

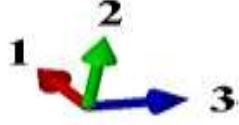

b)

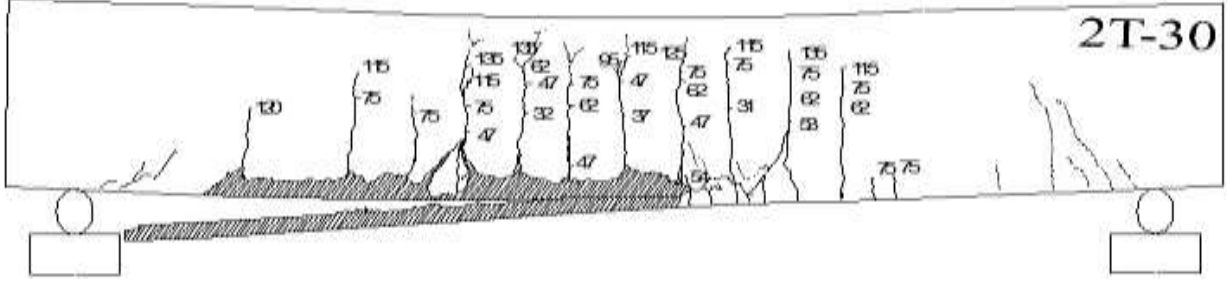

Fig. 9. a) Distribution of the concrete tensile strain of the $2 \mathrm{~T}-30$ beam based on PEEQT, PE33, and PE22 output, b) experimental crack pattern in the $2 \mathrm{~T}-30$ beam 

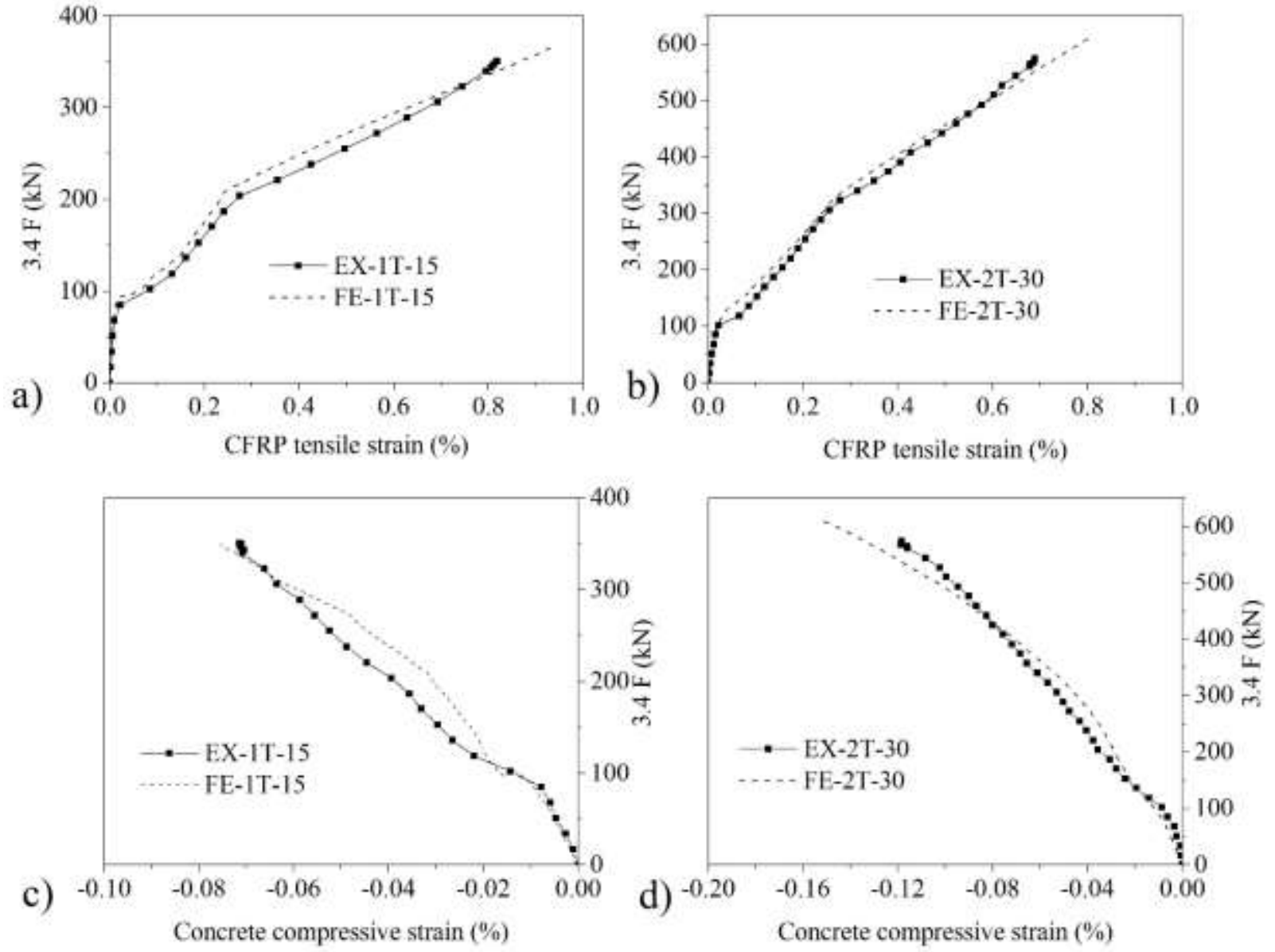

Fig. 10. Numerical simulation: tensile strains of the CFRP profile: a) 1T-15 beam, b) $2 \mathrm{~T}-30$ beam; concrete compressive strains at mid-section: c) 1T-15 beam, d) $2 \mathrm{~T}-30$ beam 

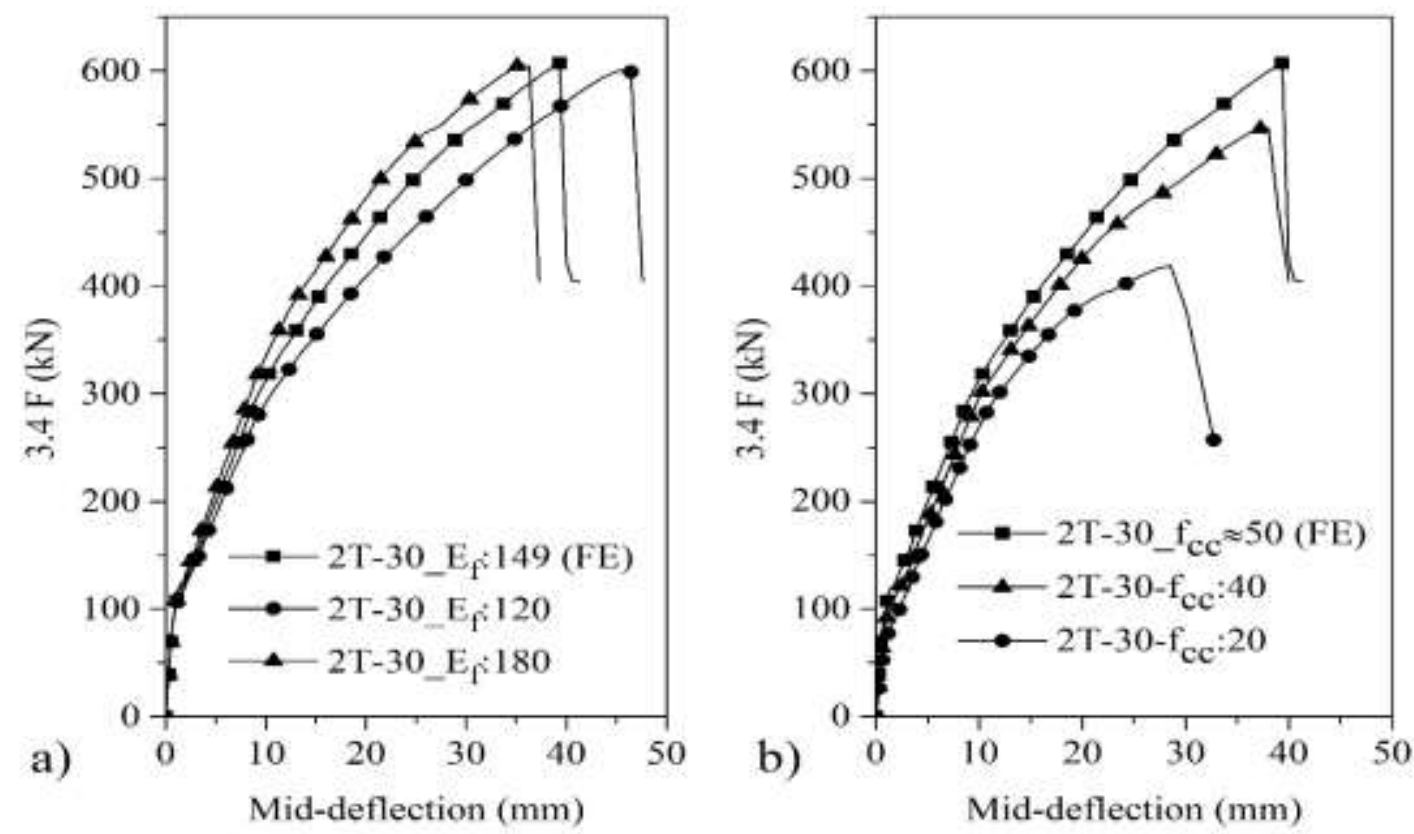

Fig. 11. The influence of the relevant parameters on the flexural response of the $2 \mathrm{~T}-30$ beam: a) CFRP elasticity modulus, b) strength characteristic of concrete 

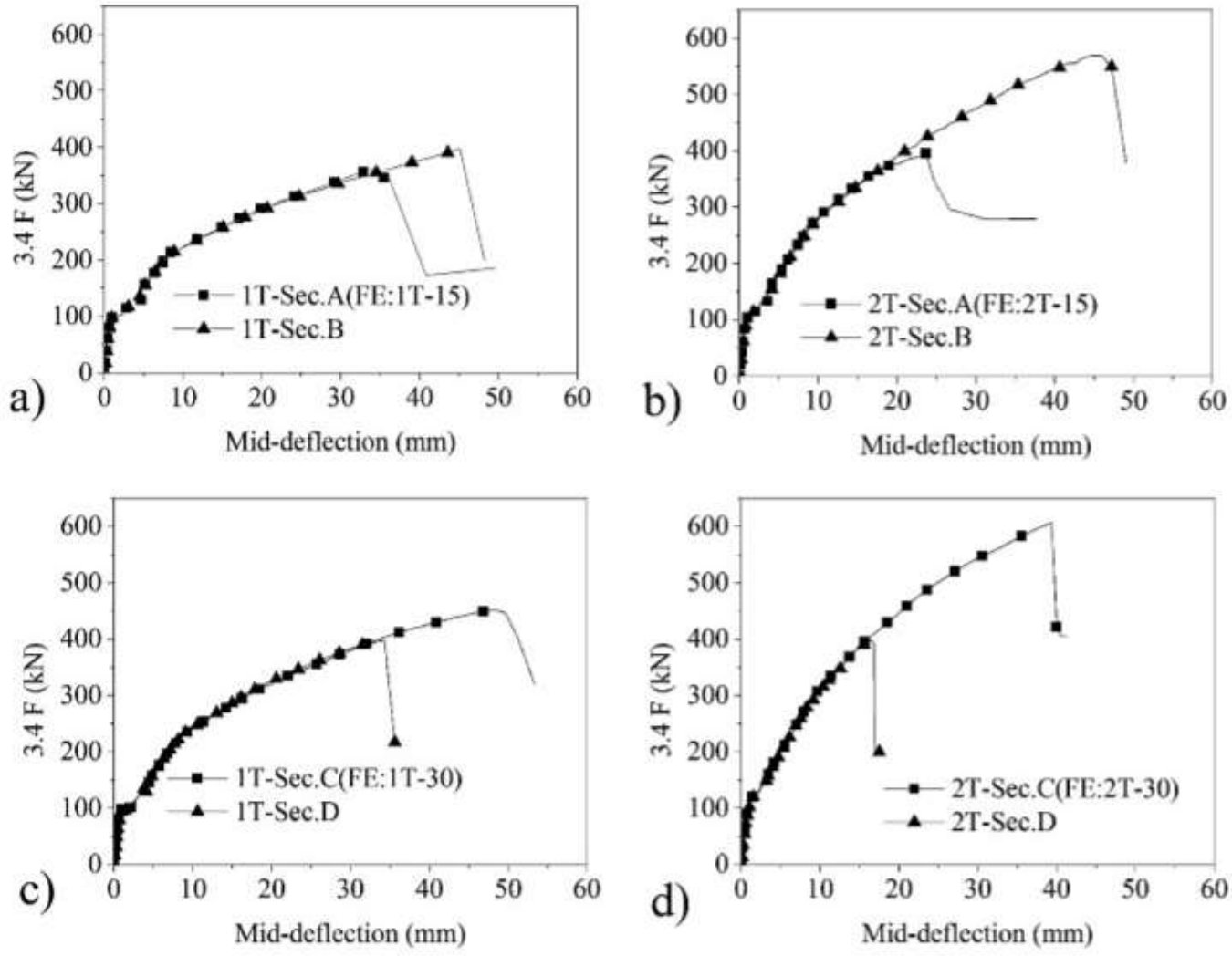

$\mathrm{A}_{\mathrm{f}}$ : cross sectional area of CFRP profile, $\mathrm{mm}^{2}$, $\mathrm{A}_{b}$ : bond contact area of CFRP profile, $\mathrm{mm}^{2} / 1 \mathrm{~mm}$,

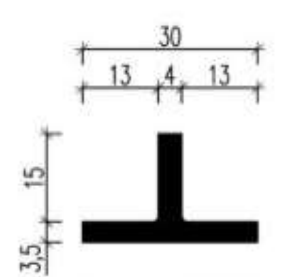

Sec.A (T15)

$$
\begin{gathered}
A_{t}=165 \\
A_{b}=60
\end{gathered}
$$$$
\mathrm{A}_{\mathrm{b}} / \mathrm{A}_{\mathrm{r}}=0.36
$$

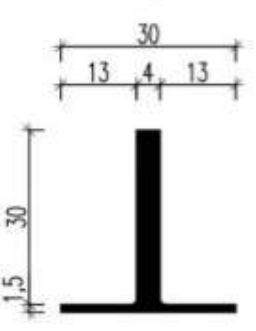

Sec.B

$\mathrm{A}_{\mathrm{F}}=165$

$\mathrm{A}_{\mathrm{b}}=90$

$\mathrm{A}_{\mathrm{b}} / \mathrm{A}_{\mathrm{F}}=0.54$

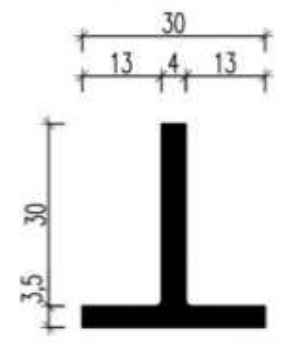

Sec.C (T30)

$$
\begin{array}{r}
A_{\mathrm{f}}=225 \\
\mathrm{~A}_{\mathrm{b}}=90
\end{array}
$$$$
\mathrm{A}_{\mathrm{b}} / \mathrm{A}_{\mathrm{r}}=0.40
$$

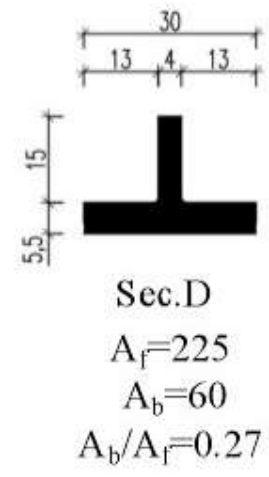

Fig. 12. Flexural responses of RC beams strengthened using CFRP profile with cross sectional area of: a) 1T-Sec.A and 1T-Sec.B, b) 2T-Sec.A and 2T-Sec.B, c) 1T-Sec.C and 1T-Sec.D, d) 2T-Sec.C and 2T-Sec.D 
Table 1 - Relevant results of the experimental program

\begin{tabular}{c|ccccccccccc}
\hline \hline \multirow{2}{*}{$\begin{array}{c}\text { Beam's } \\
\text { designation }\end{array}$} & $\begin{array}{c}3.4 F_{c r} \\
{[\mathrm{kN}]}\end{array}$ & $\begin{array}{c}\Delta_{c r} \\
{[\mathrm{~mm}]}\end{array}$ & $\begin{array}{c}3.4 F_{y} \\
{[\mathrm{kN}]}\end{array}$ & $\begin{array}{c}\Delta_{y} \\
{[\mathrm{~mm}]}\end{array}$ & $\begin{array}{c}3.4 F_{u} \\
{[\mathrm{kN}]}\end{array}$ & $\begin{array}{c}\Delta_{u} \\
{[\mathrm{~mm}]}\end{array}$ & $\begin{array}{c}\eta_{f} \\
{[\%]}\end{array}$ & $\begin{array}{c}\varepsilon_{f, f l a n g e} \\
{[\%]}\end{array}$ & $\begin{array}{c}\varepsilon_{f, w e b} \\
{[\%]}\end{array}$ & $\begin{array}{c}\eta_{\varepsilon} \\
{[\%]}\end{array}$ & Failure mode \\
\hline Reference & 78.2 & 0.7 & 136 & 4 & 5 & 6 & 7 & 8 & 9 & 10 & 11 \\
\hline $1 \mathrm{~T}-15$ & 102 & 1.5 & 204 & 8.3 & 350.2 & 36.2 & 114.6 & 0.78 & 0.80 & 74 & ICD+ BPA \\
\hline $2 \mathrm{~T}-15$ & 108.8 & 1.5 & 272 & 9.3 & 435.2 & 25.2 & 166.7 & 0.61 & 0.67 & 62 & ICD+CCS \\
\hline 1T-30 & 105.4 & 1.4 & 221 & 7.6 & 445.4 & 44.4 & 172.9 & 0.92 & 0.89 & 85 & $\begin{array}{c}\text { ICD+CCS+ } \\
\text { +LFP }\end{array}$ \\
\hline 2T-30 & 105.4 & 1.1 & 316.2 & 10.7 & 574.6 & 32.4 & 252.1 & 0.69 & 0.69 & 64 & $\begin{array}{c}\text { ICD+CCS+ } \\
\text { LFP }\end{array}$ \\
\hline $\begin{array}{l}\text { SY - steel yielding, CC - concrete crushing, ICD - intermediate crack debonding, CCS - concrete cover } \\
\text { splitting, BPA - failure of bond in profile-adhesive interface, LFP - longitudinal fracture of the profile }\end{array}$ \\
\hline
\end{tabular}


Table 2 - The adopted values for the numerical simulation

\begin{tabular}{|c|c|c|c|c|c|}
\hline \multirow{2}{*}{$\begin{array}{l}\text { Concrete } \\
\text { properties }\end{array}$} & $\begin{array}{c}f_{c c} \\
(\mathrm{MPa})\end{array}$ & $\begin{array}{c}E_{c} \\
(\mathrm{GPa})\end{array}$ & $\begin{array}{c}f_{c t} \\
(\mathrm{MPa})\end{array}$ & \multicolumn{2}{|c|}{$\begin{array}{c}G_{f} \\
(\mathrm{~N} / \mathrm{mm})\end{array}$} \\
\hline & 48.4 & 34.5 & 2.1 & \multicolumn{2}{|r|}{0.11} \\
\hline \multirow{2}{*}{$\begin{array}{c}\text { CDP } \\
\text { parameters }\end{array}$} & $\psi$ & $e$ & $\overline{f_{b 0} / f_{c 0}}$ & $\bar{~} \overline{K_{c}}$ & $\bar{V}$ \\
\hline & $40^{\circ}$ & 0.1 & 1.16 & 0.67 & 0 \\
\hline \multirow{4}{*}{$\begin{array}{l}\text { Interface } \\
\text { properties }\end{array}$} & \multirow[t]{2}{*}{$\begin{array}{l}\text { Concrete- } \\
\text { epoxy adhesive }\end{array}$} & $\begin{array}{l}\sigma_{n, \max } \\
(\mathrm{MPa})\end{array}$ & $\begin{array}{c}G_{n, f} \\
(\mathrm{~N} / \mathrm{mm})\end{array}$ & $\begin{array}{c}\tau_{\mathrm{s}, \max } \\
(\mathrm{MPa})\end{array}$ & $\begin{array}{c}G_{\mathrm{s}, f} \\
(\mathrm{~N} / \mathrm{mm})\end{array}$ \\
\hline & & 2.1 & 0.11 & 11 & 9.5 \\
\hline & \multirow{2}{*}{$\begin{array}{l}\text { CFRP profile- } \\
\text { epoxy adhesive }\end{array}$} & \multicolumn{2}{|c|}{$\begin{array}{c}\tau_{\mathrm{s}, \max } \\
(\mathrm{MPa})\end{array}$} & \multicolumn{2}{|c|}{$\begin{array}{c}G_{\mathrm{s}, f} \\
(\mathrm{~N} / \mathrm{mm})\end{array}$} \\
\hline & & \multicolumn{2}{|c|}{19.81} & \multicolumn{2}{|c|}{21.56} \\
\hline
\end{tabular}


Table 3 - The adopted values for the numerical simulation

\begin{tabular}{|c|c|c|c|c|c|}
\hline \multirow{4}{*}{ 2T-30_f $\mathrm{f}_{\mathrm{cc}}: 20$} & \multirow[t]{2}{*}{ Concrete properties } & $\begin{array}{c}f_{c c} \\
(\mathrm{MPa})\end{array}$ & $\begin{array}{c}E_{c} \\
(\mathrm{GPa})\end{array}$ & $\begin{array}{c}f_{c t} \\
(\mathrm{MPa})\end{array}$ & $\begin{array}{c}G_{f} \\
(\mathrm{~N} / \mathrm{mm})\end{array}$ \\
\hline & & 20 & 27 & 1.4 & 0.07 \\
\hline & \multirow{2}{*}{$\begin{array}{c}\text { Concrete-epoxy } \\
\text { adhesive properties }\end{array}$} & $\begin{array}{l}\sigma_{n, \text { max }} \\
(\mathrm{MPa})\end{array}$ & $\begin{array}{c}G_{n, f} \\
(\mathrm{~N} / \mathrm{mm}) \\
\end{array}$ & $\begin{array}{c}\tau_{\mathrm{s}, \max } \\
(\mathrm{MPa})\end{array}$ & $\begin{array}{c}G_{\mathrm{s}, f} \\
(\mathrm{~N} / \mathrm{mm})\end{array}$ \\
\hline & & 1.4 & 0.07 & 6.44 & 5.6 \\
\hline \multirow{4}{*}{ 2T-30_f $\mathrm{f}_{\mathrm{cc}}: 40$} & \multirow[t]{2}{*}{ Concrete properties } & $\begin{array}{c}f_{c c} \\
(\mathrm{MPa})\end{array}$ & $\begin{array}{c}E_{c} \\
(\mathrm{GPa})\end{array}$ & $\begin{array}{c}f_{c t} \\
(\mathrm{MPa})\end{array}$ & $\begin{array}{c}G_{f} \\
(\mathrm{~N} / \mathrm{mm})\end{array}$ \\
\hline & & 40 & 33.5 & 1.9 & 0.10 \\
\hline & \multirow{2}{*}{$\begin{array}{l}\text { Concrete-epoxy } \\
\text { adhesive properties }\end{array}$} & $\begin{array}{l}\sigma_{n, \text { max }} \\
(\mathrm{MPa})\end{array}$ & $\begin{array}{c}G_{n, f} \\
(\mathrm{~N} / \mathrm{mm})\end{array}$ & $\begin{array}{c}\tau_{\mathrm{s}, \max } \\
(\mathrm{MPa})\end{array}$ & $\begin{array}{c}G_{\mathrm{s}, f} \\
(\mathrm{~N} / \mathrm{mm})\end{array}$ \\
\hline & & 1.9 & 0.10 & 9.7 & 8.44 \\
\hline
\end{tabular}

